\title{
The Somatotopic Organization of the Supplementary Motor Area: Intracortical Microstimulation Mapping
}

\author{
Andrew R. Mitz and Steven P. Wise \\ Laboratory of Neurophysiology, National Institute of Mental Health, Bethesda, Maryland 20892
}

\begin{abstract}
The somatotopic organization of the supplementary motor area (SMA) is commonly held to consist of a rostrocaudal sequence of orofacial, forelimb, and hindlimb representations. Recently, however, this somatotopy has been questioned. Studies of regional cerebral blood flow in humans and the movements evoked by intracortical electrical stimulation in cynomolgus monkeys have been unable to reveal evidence of distinct orofacial, forelimb, and hindlimb representations rostrocaudally situated along the medial cortex of the hemisphere. Partly on the basis of those results, it has been suggested that the SMA functions as a nontopographically organized "higher-order" motor center. The present study reexamines SMA organization by observing stimulation-evoked movements. The medial frontal cortex of 2 rhesus monkeys was mapped using a modified intracortical microstimulation technique. We observed a forelimb representation mainly on the medial surface of the hemisphere in both animals. Rostral or rostrolateral to the forelimb representation, depending on the individual, we evoked orofacial movements (including eye movements). Hindlimb movements were evoked from tissue overlapping, but largely caudal to, the forelimb representation. Thus, we conclude that there is a clear rostrocaudal progression of orofacial, forelimb, and hindlimb movement representations in the SMA.
\end{abstract}

Woolsey's classic picture of supplementary motor area (SMA) somatotopy (Woolsey et al., 1952) has been questioned recently on the basis of both a regional cerebral blood flow study in humans (Orgogozo and Larsen, 1979) and a microstimulation study in monkeys (Macpherson et al., 1982a). In neither of those studies did the investigators observe any clear somatotopic organization in the SMA. For example, Macpherson et al. found a "caudal concentration of hindlimb points" with microstimulation but concluded that their results "did not support Woolsey's concept of a somatotopic rostrocaudal sequence of face, forelimb and hindlimb representation" (Macpherson et al., 1982a, p. 415).

Despite the doubts raised by those recent microstimulation and blood flow studies, examination of neuronal discharge (Brinkman and Porter, 1979; Tanji and Kurata, 1982) and the

\footnotetext{
Received June 20, 1986; revised Sept. 15, 1986; accepted Oct. 17, 1986.

The authors thank William G. Benson for preparation of the histological material, and Dr. Robert E. Burke of the Laboratory of Neural Control for the use of his laboratory's cell plotting system.

Correspondence should be addressed to Andrew R. Mitz, Laboratory of Neurophysiology, NIH, Building 36, Room 2D10, Bethesda, MD 20892.

Copyright (C) 1987 Society for Neuroscience $0270-6474 / 87 / 041010-12 \$ 02.00 / 0$
}

pattern of corticocortical connections (Jones and Powell, 1969; Pandya and Vignolo, 1971; Künzle, 1978; Muakkassa and Strick, 1979; Godschalk et al., 1984) in various macaque species support Woolsey's view of somatotopy within the SMA. Further, the region of the SMA projecting to cervical spinal segments appears to be rostral to the region that projects to lumbar segments (Murray and Coulter, 198 1; cf. Macpherson et al., 1982a, b).

However, the available data do not lead to unequivocal conclusions about SMA topography. The anatomical studies cited above, with the exception of that of Godschalk et al., rely upon comparison of labeling or staining patterns among several individuals in a species. Thus, it is possible to reject the anatomical evidence for SMA somatotopy on the grounds that comparing data from different individuals undermines conclusions about somatotopy, especially in such a small cortical field. While the multiple label study of Godschalk et al. addresses the problem adcquatcly from a tcchnical pcrspcctivc, rclevant connectional data are reported only from 1 animal, and SMA topography was neither the focus of their study nor was it discussed in their report. As for physiological results reporting somatotopy (Brinkman and Porter, 1979; Tanji and Kurata, 1982), these too have limitations that have allowed the adoption of a nontopographic model of SMA organization. The work of Brinkman and Porter did not include sufficient behavioral control to identify orofacial, hindlimb, and forelimb movements separately. Further, the exact location of their recording sites in relation to sulcal landmarks or cytoarchitectonic boundaries was inadequately presented in their report. As for the work of Tanji and Kurata, since they did not systematically examine orofacial movements, their conclusions concerning somatotopy rested upon the distinct location of neurons active before hindlimb movements and those active before forelimb movements. But the lack of a clear histological or physiological boundary between the hindlimb representations of the primary motor cortex and SMA prevents the unequivocal identification of an SMA hindlimb representation necessary for their conclusion.

It is presumably for the above reasons that the physiological and anatomical evidence for SMA somatotopy has been rejected by prominent reviewers of the SMA literature (Eccles, 1982; Eccles and Robinson, 1984; Wiesendanger and Wiesendanger, 1984; Wiesendanger, 1986). That view of the literature has contributed to the suggestion that the SMA functions as a nontopographically organized "supramotor" center (Orgogozo and Larsen, 1979; Eccles, 1982; Eccles and Robinson, 1984). In view of the discrepancy between classically accepted and more recent views of SMA organization, we decided to reinvestigate the issue of SMA somatotopy with a method having different interpretational limitations than those previously applied. 


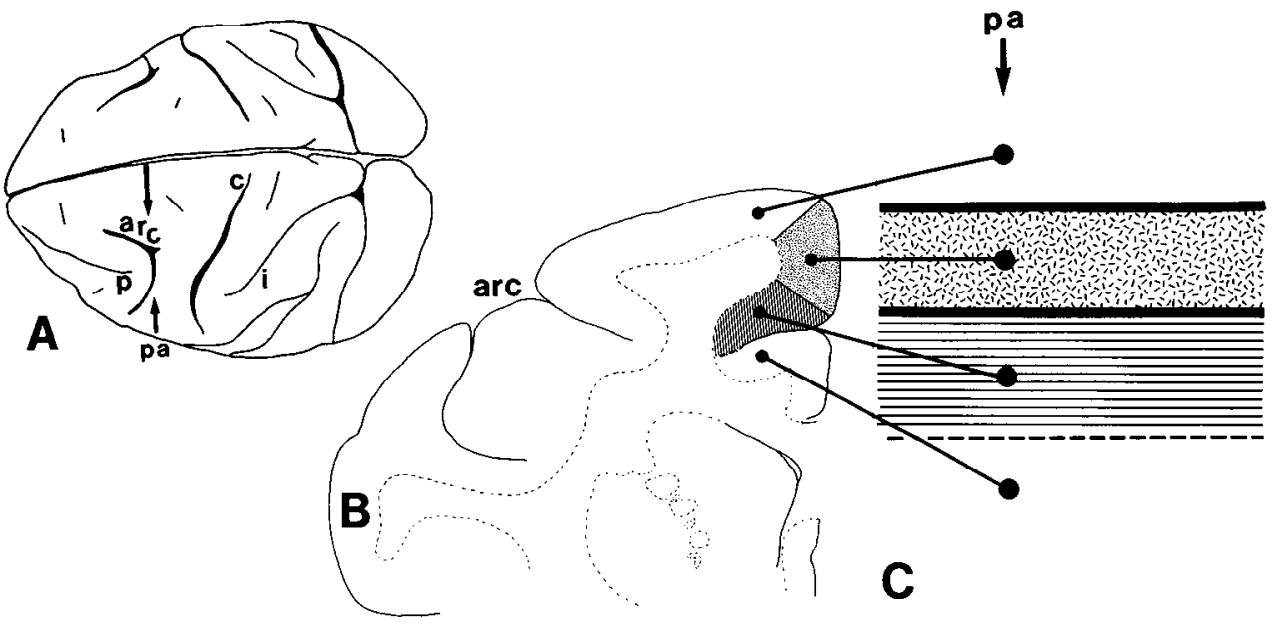

Figure 1. Reconstruction method. $A$, Oblique dorsolateral view of the cerebrum of the second monkey used in this study. Arrows point to the posterior limit of the arcuate sulcus (posterior arcuate, $p a)$. Sulci: $p$, principle; arc, arcuate; $c$, central; $i$, intraparietal. $B$, Frontal section taken approximately at the level of $p a$. The medial wall of the hemispherc is stippled and the dorsal bank of the cingulate sulcus is striped to correspond to the unfolded view in $C . C$, Unfolded view of medial cortex. Rostral is to the left. Top to bottom: convexity of hemisphere (white), adjacent medial wall (stippled), dorsal bank of cingulate sulcus (striped), and the ventral bank of the cingulate (white). pa marks the rostrocaudal level of the section in $B$.

\section{Materials and Methods}

Two rhesus monkeys (Macaca mulatta) were used in this experiment: The first monkey was a $6 \mathrm{~kg}$ female and the second monkey a $12 \mathrm{~kg}$ male. Both monkeys had undergone operant conditioning unrelated to the current experiment. The first monkey was used for a single-unit recording study prior to SMA mapping.

Surgery. Each animal was anesthetized with sodium pentobarbital $(30 \mathrm{mg} / \mathrm{kg})$, and a stainless steel recording chamber $(27 \times 27 \mathrm{~mm}$ for the first monkey, $28 \times 48 \mathrm{~mm}$ for the second) was cemented to the skull. Head bolts were implanted in the skull in the same procedure. Throughout this study, food and water were available ad libitum except for a 2-4 hr period, $5 \mathrm{~d}$ a week when the monkey was in a primate chair. In all respects the monkeys were cared for in the manner prescribed in Guiding Principles in the Care and Use of Animals of the American Physiological Society.

Microstimulation. Two types of electrode were used for stimulation: (1) glass-insulated platinum-iridium electrodes with exposed tips of 7.5$12.5 \mu \mathrm{m}$, tip surface areas of $120-200 \mu \mathrm{m}^{2}$, and impedances of 1-3 $\mathrm{M} \Omega$ (at $1 \mathrm{KHz}$ ), and (2) otherwise identical electrodes with tip exposures of between 15 and $20 \mu \mathrm{m}$, surface areas between 600 and $1100 \mu \mathrm{m}^{2}$, and impedances between $100 \mathrm{~K} \Omega$ and $1.2 \mathrm{M} \Omega$. For ease of description, stimulation through the large-exposure electrodes will be termed "modified" microstimulation to distinguish it from "standard" microstimulation with the small-exposure electrodes.

Trains of 11-31 constant-current pulses were delivered at 330 pulses/ sec through a biphasic stimulator (Mitz, 1984). Each phase was $0.2 \mathrm{msec}$ in duration (cathodal first) and both phases were symmetrical in amplitude. Currents were sensed by a differential recording amplifier across a $100 \Omega$ resistor in series with the return lead of the stimulator. The amplified current signal was monitored on a digital oscilloscope.

Current intensities for standard microstimulation were usually limited to $35 \mu \mathrm{A}$ and for modified microstimulation, $65 \mu \mathrm{A}$. All data presented were obtained by stimulation within these limits.

Electromyography. Surface EMG recordings were made during stimulation at selected sites. Gold-plated disc electrodes (Grass E5GH) were placed on the skin and signals were amplified and filtered using a Grass 7P511G amplifier. During stimulation EMGs were monitored on an oscilloscope and stored on a Data Precision 6000 waveform analyzer. Some EMG signals were Paynter filtered $(50 \mathrm{msec}$ time constant; see Gottlieb and Agarwal, 1970) before storage.

Cortical exploration. The SMA was explored systematically in 3 hemispheres of the 2 monkeys. In the first monkey, only the left hemisphere was explored systematically, but because of the angle of electrode penetration $\left(25^{\circ}\right.$ from the vertical, advancing to the right with increased depth), some data were also collected from the medial wall of the right hemisphere and dorsal bank of the right cingulate sulcus. In the second monkey both hemispheres were explored with vertical electrode trajectories. In both animals, transdural electrode penetrations were made in a $1.0 \times 1.0 \mathrm{~mm}$ grid extending from 2 to $7 \mathrm{~mm}$ lateral to the midline over a $22 \mathrm{~mm}$ rostrocaudal extent of the superior frontal gyrus. Within each penetration, modified microstimulation was tested every $250 \mu \mathrm{m}$ or less to a depth of $11 \mathrm{~mm}$ or more. Penetrations where standard microstimulation was tested proceeded with an identical protocol. Electrode pentrations were made over a period of 3 months in each hemisphere explored, and no more than eight penetrations were made per day.

In about $10 \%$ of the penetrations, single-unit and multiunit recordings were made at each depth to test tactile and joint receptive fields. The impedance of each electrode was tested in situ at the start and end of every track. An electrode was discarded if its recording characteristics changed or if its impedance changed by more than $25 \%$ during the course of stimulation. Generally, electrodes were used for 1-3 tracks. About half the electrodes were examined microscopically before and after use. A track was repeated several days later if the electrode originally used for that track showed evidence of unusual wear or damage.

While the monkey sat in a primate chair facing forward with the head restrained, 2 observers scanned the entire animal for evoked movements. To aid observation an open-frame, rotating chair was employed. At each electrode depth, stimuli were delivered repeatedly at $35 \mu \mathrm{A}$ (standard electrodes) or $65 \mu \mathrm{A}$ (modified electrodes). Stimulation continued until all joints and most facial muscles were checked.

Movements evoked with intracortical stimulation were recorded only if movements were clearly identified by 2 observers, observers agreed on the details of the observed movements, and movements were evoked repeatedly from the same site. Once movements were identified at a given site, the threshold for each movement was determined. Movement threshold was defined as the current at which the movement was evoked on approximately half of the stimulus presentations. In many cases, movements evoked during initial descent of the electrode were compared with those observed during the subsequent ascent of the electrode. When movements could be evoked during electrode ascent, the descending sequence of movements was, with very few exceptions, confirmed. We also reexamined microstimulation effects at selected penetrations after several weeks of mapping had intervened. In 12 tracks where movements were evoked during the repeat penetration, 10 of these tracks evoked the same movements as in the original penetration.

When ketamine was used during mapping, it was administered at a dose of $1.0-2.0 \mathrm{mg} / \mathrm{kg}$, i.m., every $45-120 \mathrm{~min}$ as necessary to reduce the frequency of spontaneous movements by the animal. Doses were generally delivered between electrode penetrations. Over the 2-4 hr sessions, ketamine administrations never exceeded $1.3 \mathrm{mg} / \mathrm{kg} / \mathrm{hr}$.

Histological analysis and reconstruction of stimulation sites. Following stimulation mapping, the animals were deeply anesthetized with pentobarbital and perfused with a buffered formaldehyde solution. During the perfusion, 5 pins were inserted at known coordinates, $8 \mathrm{~mm}$ apart, to aid in localization of the stimulation sites. Each hemisphere was removed, photographed, sectioned on a freezing microtome at 30 $\mu \mathrm{m}$ in the frontal plane, and stained with thionin. The reconstructed trajectory of each penetration was plotted onto drawings of sections taken at $120 \mu \mathrm{m}$ intervals and was based upon the original chamber coordinates, marking pin locations, surface landmarks, and recording data. Based on this reconstruction, any response evoked from the white matter was excluded from the analysis. The stimulation sites were then plotted onto a 2-dimensional map of the medial frontal cortex (Fig. 1). In 1 hemisphere, a substantial area of gliosis was found in the stimulated 
region. This zone, which contained few histologically normal neurons, is plotted in the hatched box of Figure 5.

The boundary between cytoarchitectonic areas 4 and 6 of the agranular frontal cortex was first estimated qualitatively. Based on previous cytoarchitectonic studies in monkeys (Brodmann, 1905, 1909; von Bonin and Bailey, 1947), the cortex lacking or virtually lacking the very large layer V (Betz) cells found in more caudal regions was taken to be area 6 . The region containing such cells was considered to be area 4 . Measurements were then made of neurons in the left hemisphere of the second monkey. Using a computerized cell plotting system, ${ }^{1}$ cell body areas were measured in 21 sections separated by approximately $500 \mu \mathrm{m}$ and covering a $10 \mathrm{~mm}$ rostrocaudal extent. An area, $1 \mathrm{~mm}$ in dorsoventral extent and centered midway between the dorsal surface of the hemisphere and the cingulate sulcus, was sampled for cell measurement. Each cell body greater than $20 \mu \mathrm{m}$ in any dimension was magnified by a factor of 400 and circumscribed with the aid of a digitizing pad. Cell perimeter coordinates were collected by the computer, which then computed the area of the cell body. Any stained portion of the proximal dendrites was included in the cell area measurement.

\section{Results}

\section{Cytoarchitectonics}

The qualitatively determined boundary between cytoarchitectonic area 4 and area 6 for the left hemisphere of the second monkey was determined to be $7 \mathrm{~mm}$ caudal to the posterior limit of the arcuate sulcus. The area 4/area 6 boundary was similarly located in the other hemispheres studied. All of the stimulated region of each hemisphere was in the frontal agranular cortex, including the most rostrally situated stimulation sites.

Figure 2 shows the rostrocaudal distributions of large cell bodies (greater than $600 \mu \mathrm{m}^{2}$ ) and of the largest cell bodies $\left(>1200 \mu \mathrm{m}^{2}\right)$ based upon cell area measurements in the left hemisphere of the second monkey. Both neural populations are sparse rostral to the $7 \mathrm{~mm}$ point (the qualitative area 4/area 6 boundary) and decrease from a peak to low densities over a 4$5 \mathrm{~mm}$ range. The inset graph of Figure 2 shows that neurons with areas of $300-500 \mu \mathrm{m}^{2}$ do not have the same rostrocaudal change in density. Neurons with cell body areas less than 300 $\mu \mathrm{m}^{2}$ were not systematically studied.

\section{Preliminary stimulation}

Preliminary experiments were undertaken to find stimulation parameters best suited for mapping the SMA. Standard microelectrodes were used. In agreement with previous reports (Macpherson et al., 1982a; Schlag and Schlag-Rey, 1985), sites from which movements could be evoked were difficult to locate with standard microstimulation. $\Lambda$ n evoked response often disappeared with small changes in electrode position. In order to aid the localization of sites responsive to electrical stimulation, larger stimulation currents (above $35 \mu \mathrm{A}$ ) were tested. Since gas formation at the electrode-tissue interface and neuronal depression are associated with excess current delivered to an electrode (Lilly et al., 1952; Asanuma and Arnold, 1975), modified electrodes were fabricated with a 10 -fold greater surface area than electrodes commonly used for intracortical microstimulation. Increasing electrode surface area reduces the current density at the tip, thus reducing the very sharp voltage gradients near it and allowing the safe application of higher currents (Lilly et al., 1952; Asanuma et al., 1981).

\footnotetext{
I This system was developed by the Laboratory of Neural Control in the National Institute of Neurological and Communicative Disorders and Stroke. The system allows simultaneous viewing of high-power microscopic images and computergenerated vector graphics to repeatedly locate, identify, and measure individual cells on a series of histological sections.
}

Variations of certain stimulus parameters other than stimulus current were tested. While testing various pulse train lengths, it was noted that those longer than $50 \mathrm{msec}$ were more effective in the SMA than the shorter pulse trains (30-40 msec) effective in the primary motor cortex (Asanuma et al., 1976). After preliminary testing, $100 \mathrm{msec}$ pulse trains were chosen for mapping. Small $(50 \mu \mathrm{sec})$ variations in pulse duration from the optimum (200 $\mu \mathrm{sec}$ ) determined empirically in cats (Stoney et al., 1968) did not appear to affect the thresholds of evoked movements when biphasic stimulation was used. Monophasic stimulation was not tested. Similarly, since repetition rates of 300-400 pulses/ sec (Asanuma and Ward, 1971; Asanuma et al., 1976) appeared sufficient for SMA stimulation, variations in that parameter were also not tested.

Evoked responses were more labile during SMA stimulation than during comparable stimulation of the primary motor cortex. Two techniques increased the likelihood of observing responses at a stimulus site: (1) Stimuli were delivered at nonuniform intervals, and (2) each animal was lightly tranquilized with ketamine hydrochloride during stimulation.

Following these preliminary tests, microstimulation mapping began using $100 \mathrm{msec}$ trains, approximately $1000 \mu \mathrm{m}^{2}$ electrode tips, and ketamine (up to $1.3 \mathrm{mg} / \mathrm{kg} / \mathrm{hr}$; see Materials and Methods). Movements were reliably evoked from the SMA and the nearby hindlimb representation of the primary motor cortex with these stimulation parameters.

\section{Thresholds}

With modified microstimulation, threshold distributions did not differ substantially between area 4 and area 6 . Movements were evoked with under $10 \mu \mathrm{A}$ of current in both areas. Three cases are examined in Figure 3: combined data from the left and right hemispheres of the first monkey (see Materials and Methods) and separate data from the left and right hemispheres of the second monkey. Each histogram is based upon the lowest threshold at active cortical sites in area 4 or area 6 . While threshold means for area 4 are lower than the means for area 6 in each of the 3 cases, the differences are not significant ( $t$ test; 2-tailed, $p>0.1$ ) in 2 of the 3 cases examined. Thus, a clear distinction between area 4 and area 6 on the basis of thresholds was deemed unfeasible with the present modified microstimulation technique.

\section{Movements evoked}

Two general classes of evoked movements were identified. The first class consisted of brief, short-latency movements characteristic of those traditionally associated with primary motor cortex stimulation (Fritsch and Hitzig, 1870; Leyton and Sherrington, 1917; Penfield and Boldrey, 1937). This class was by far the most common response, observed for over $90 \%$ of the evoked movements. Movements of the second class were slow in developing. The movement time from the peak excursion to the termination of these movements was equally slow, like a highly damped mechanical system. In addition, movements intermediate between these 2 classes were also observed.

Movement sites within area 6 were classified by the complexity of the evoked movements at each site. At "simple" cortical sites, either a single-joint movement was evoked or movement was restricted to the digits of 1 extremity. At "contiguous" joint sites, movements occurred at 2 or more adjacent joints. Multiple orofacial movements were classified as contiguous. At "noncontiguous" sites, evoked movements involved 


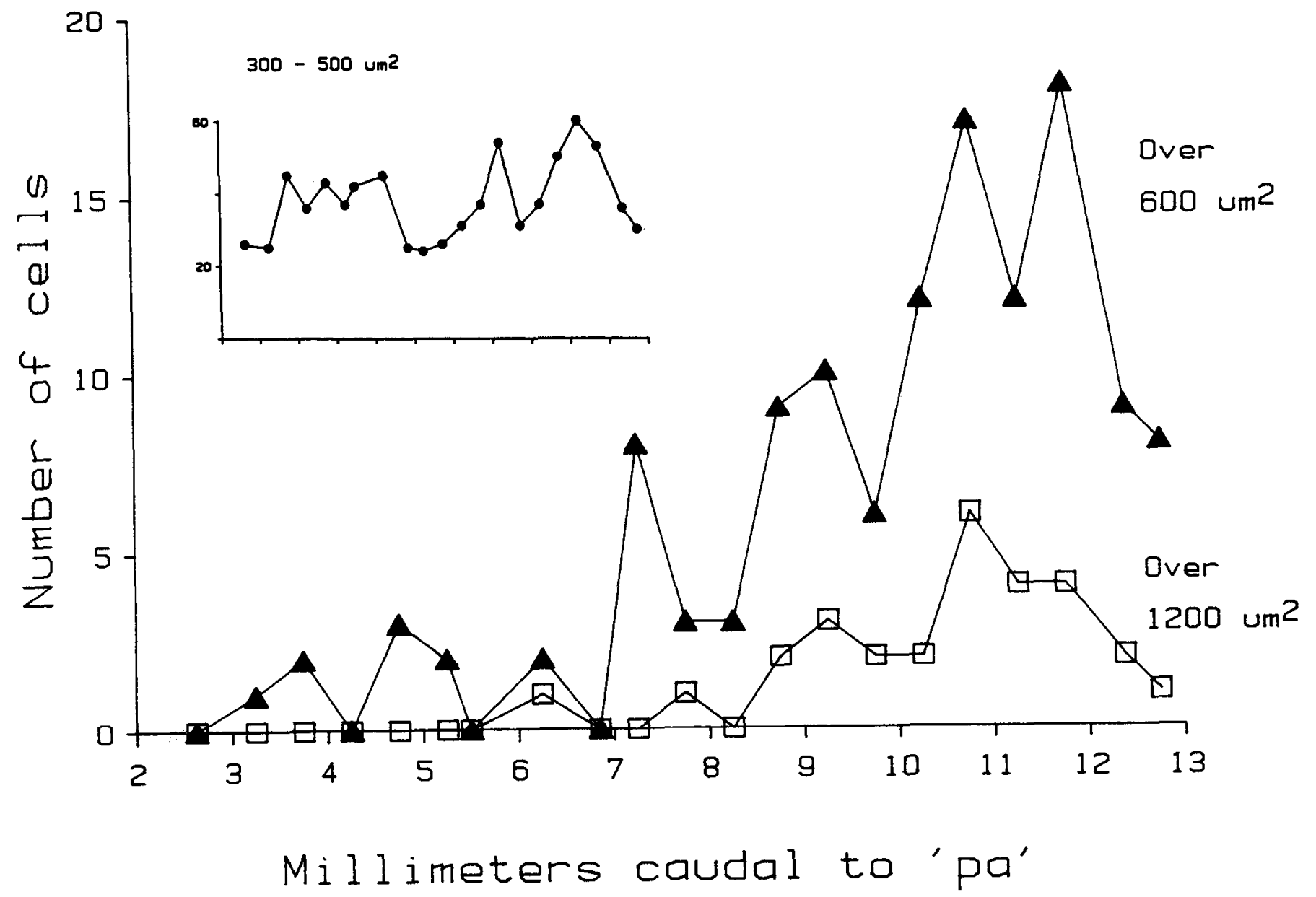

Figure 2. Rostrocaudal distributions of neurons with cell body areas over $300 \mu \mathrm{m}^{2}$. Data arc from the left dorsomedial cortex of the second monkey. On each of 21 frontal sections, covering about $10 \mathrm{~mm}$ rostrocaudally, cell body area measurements were made of the largest cells in a $1.0-\mathrm{mm}$-wide cortical strip. The number of cells of a given size in each strip is plotted as a function of rostrocaudal position relative to pa. The independently determined qualitative area $4 / 6$ boundary is at 7.0 on the rostrocaudal axis (abscissa). Symbols: filled triangles, cell bodies with areas $>600 \mu \mathrm{m}^{2}$; open squares, areas $>1200 \mu \mathrm{m}^{2} ;$ filled circles (inset), areas between 300 and $500 \mu \mathrm{m}^{2}$.

nonadjacent joints. The majority of sites in area 6 were simple movement sites (Table 1). Noncontiguous sites were the least common.

Although movements confined to the fingers were classified as simple, most finger movements included more than 1 digit and multiple joints within each digit. Thumb movements, independent of other digit movements, were observed at only 5 sites. At 3 of these, wrist movements were also evoked.

At certain individual sites, 2 or 3 different movement patterns were evoked, switching from stimulus to stimulus. In such instances different patterns always involved the same joint(s). EMG recordings made during microstimulation at several sites involving multiple movement patterns confirmed that a distinct muscle activity pattern was associated with each of the movement patterns. This effect was identified at fewer than $5 \%$ of the stimulus sites; however, no systematic attempt was made during the course of the experiment to identify these sites.

\section{Pattern of evoked movements}

Stimulation of medial area 6 and adjacent area 4 most commonly evoked either contralateral limb or bilateral orofacial, eye, or axial movements in a rostrocaudally oriented somatotopic pattern.
The map of evoked movements shown in Figure 4 is based upon data collected during 136 penetrations into the left hemisphere of the second monkey and is presented in the format of Figure $1 C$. Figure 5 is a map based upon 67 penetrations into the right hemisphere of the same animal. Figure 6 is from 111 penetrations into the left hemisphere of the first monkey. (About $10 \%$ of the data in Fig. 6 are from the right hemisphere of that

Table 1. Complexity of movements evoked from the SMA

\begin{tabular}{|c|c|c|c|c|}
\hline \multirow[b]{2}{*}{ Case } & \multicolumn{3}{|c|}{ Percentage of cortical sites } & \multirow{2}{*}{$\begin{array}{l}\text { Total } \\
\text { number } \\
\text { of sites }\end{array}$} \\
\hline & "Simple" & $\begin{array}{l}\text { "Contig- } \\
\text { uous" }\end{array}$ & $\begin{array}{l}\text { "Noncon- } \\
\text { tiguous" }\end{array}$ & \\
\hline \multicolumn{5}{|l|}{ First monkey } \\
\hline combined & 51 & 33 & 16 & 96 \\
\hline \multicolumn{5}{|l|}{ Second monkey } \\
\hline Left cortex & 54 & 35 & 11 & 106 \\
\hline Right cortex & 72 & 19 & 9 & 57 \\
\hline
\end{tabular}

Movements evoked from each cortical site were classified as simple (single joint or restricted to the digits of 1 extremity), contiguous (adjacent joints or facial movements), and noncontiguous (nonadjacent joints). For each case, percentages were calculated based upon the total number of active sites within area 6 . 


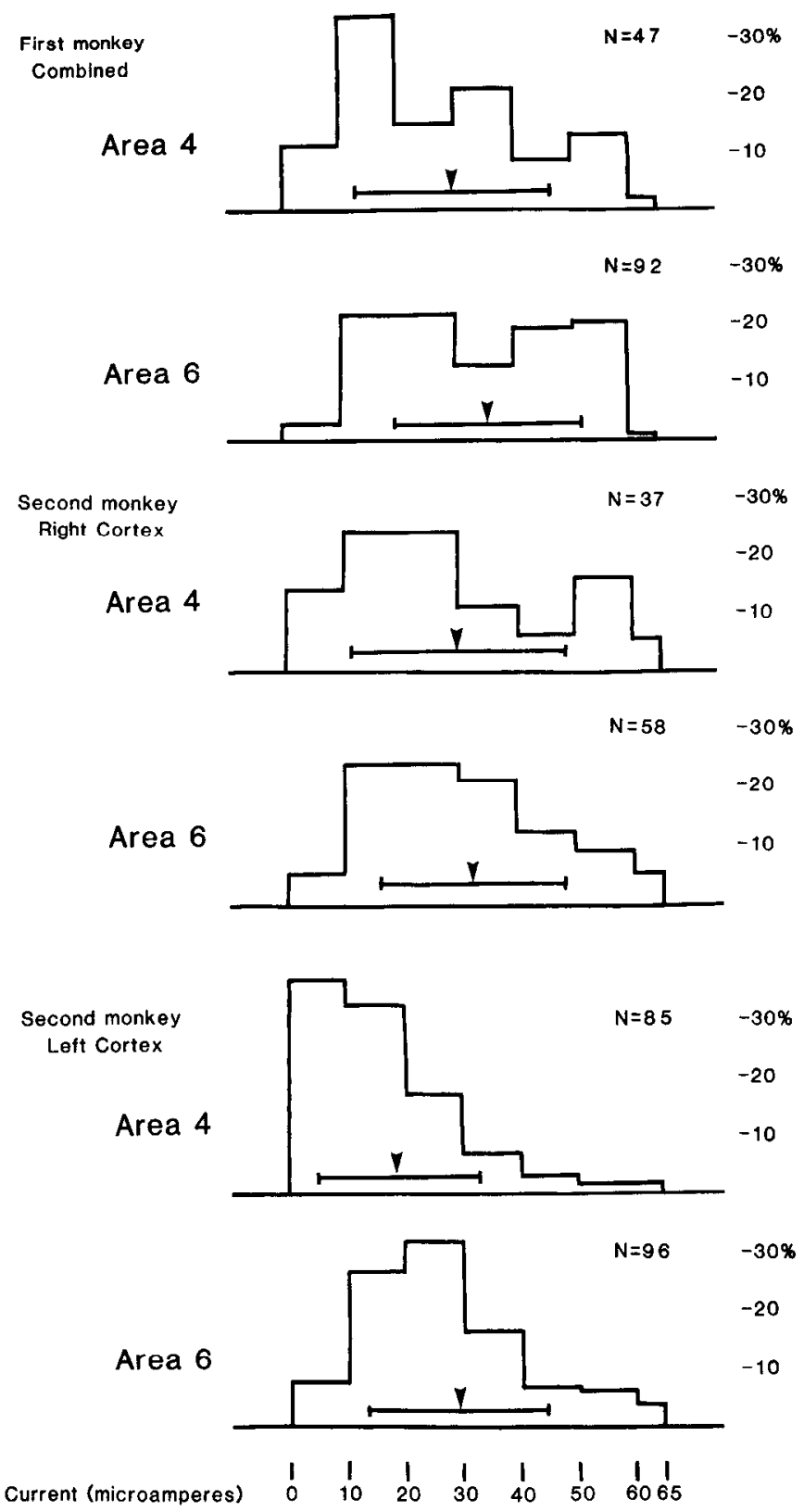

Figure 3. Distribution of movement thresholds: area 4 versus area 6 . Threshold histograms for area 4 and area 6 are shown for 3 cases: (1) combined data from the right and left hemispheres of the first monkey and (2) data from the right and (3) left hemispheres of the second monkey. Each histogram is normalized for the total number of sites from which movements were evoked, as indicated on each plot. Each bin is $10 \mu \mathrm{A}$ except for the last $(5 \mu \mathrm{A})$. Arrowheads mark the mean threshold value $+1 \mathrm{SD}$

monkey; see Materials and Methods.) All 3 movement maps (Figs. 4-6) show an orderly rostrocaudal sequence of representation: Orofacial movements (circles) are represented most rostrally, followed sequentially by forelimb (filled triangles), and then hindlimb (squares) movements. These 3 representations each span from the dorsal bank of the cingulate sulcus to the medial surface of the hemisphere and at least $2 \mathrm{~mm}$ onto the hemispheric convexity. Note that the medial surface of the hemisphere is represented as the area between the 2 essentially horizontal solid lines in our reconstruction.

Orofacial movements were evoked from a $6 \mathrm{~mm}$ rostrocaudal

\begin{tabular}{|c|c|c|c|c|}
\hline & Percentage of $\mathrm{m}$ & vements & & \\
\hline Case & $\begin{array}{l}\text { Convex- } \\
\text { ity of } \\
\text { hemi- Medial } \\
\text { sphere cortex }\end{array}$ & $\begin{array}{l}\text { Dorsal } \\
\text { bank of } \\
\text { cingu- } \\
\text { late }\end{array}$ & $\begin{array}{l}\text { Ventral } \\
\text { bank of } \\
\text { cingulate }\end{array}$ & $\begin{array}{l}\text { Total } \\
\text { number }\end{array}$ \\
\hline
\end{tabular}

First monkey

Combined

Proximal

Distal

Second monkey

Left cortex

Proximal

Distal

Right cortex

Proximal

Distal

$\begin{array}{ll}2 & 87 \\ 5 & 84\end{array}$

9

2

45

$\begin{array}{lll}8 & 3 & 38\end{array}$

Proximal (elbow, shoulder) and distal (fingers, wrist, forearm) forelimb movement distributions are shown for the convexity of the hemisphere, the adjacent medial cortex, and the dorsal and ventral banks of the cingulate sulcus. In each of the 3 cases from the 2 monkeys percentages are calculated independently for proximal and for distal movements. Percentages in each row are based upon the total number of movements for that row.

extent of the medial cortex and were contained entirely within area 6 . Rostrally within the orofacial representation is a region from which conjugate saccadic eye movements (circles around dots) were evoked. Eye movements were directed toward the contralateral visual hemifield, and movement direction appeared to be independent of initial eye position. These eye movements were not associated with observable neck muscle activity; however, head movement was difficult to identify with the head restrained. Other orofacial movements included both contra- and bilateral movements of the lips (upper or lower lip movement up and down, displacement of the lips towards the contralateral angle of the mouth), pinnae (protraction, retraction), nostrils (flair), eyelids (opening, closing), tongue (protrusion and other, difficult-to-identify movements), jaw (opening, closing, lateral movements), and other facial musculature (periorbital, scalp). Absent were movements of the vibrissa and vocalizations. Aside from the rostral cortical location of eye movement sites, no fine-grain somatotopy within the orofacial area was discerned. The lowest threshold face movement (nose flair) required $7 \mu \mathrm{A}$; the lowest threshold eye movements, 12 $\mu \mathrm{A}$.

The bulk of the forelimb representation covered about $8 \mathrm{~mm}$ rostrocaudally, overlapping the region of orofacial movement sites rostrally by $1-3 \mathrm{~mm}$ and hindlimb sites caudally by 2-6 $\mathrm{mm}$. Virtually all forelimb sites on the hemispheric convexity and adjacent medial surface were within area 6 . Forelimb sites in the cingulate sulcus were at approximately the same rostrocaudal level. Evoked forelimb movements included finger (flexion and extension of all digits, adduction and abduction of the thumb), wrist (flexion, extension, ulnar and radial deviations), forearm (pronation, supination), elbow (flexion, extension), and shoulder (flexion, extension, adduction, abduction, internal and external rotations, elevation, depression) movements. Almost all of these were evoked at one or more sites with $\leq 20 \mu \mathrm{A}$ current. Certain movements-namely, flexion, ulnar or radial deviation of the wrist, and adduction or depression of the shoul- 


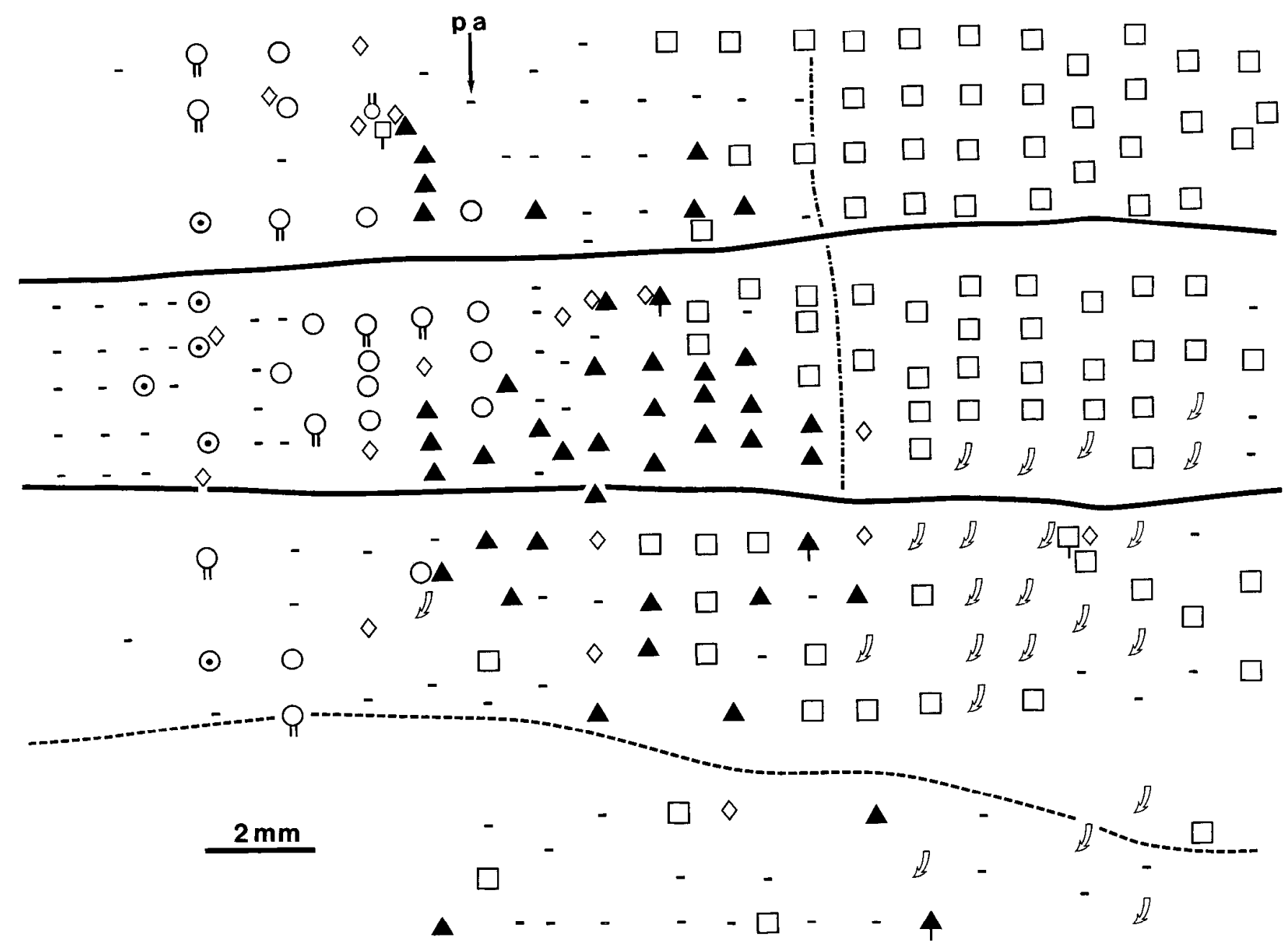

Figure 4. SMA somatotopy of the left hemisphere of the second rhesus monkey. Rostral is to the left. (See Fig. 1 for reconstruction method.) Movement symbols: circle, orofacial; circle with dot, conjugate eye movement; diamond, axial; filled triangle, forelimb; square, hindlimb; curved arrow, tail; dash, no movement. Vertical lines on symbols; 1 line, ipsilateral movement; 2 lines, bilateral movement. pa marks the posterior limit of the arcuate sulcus. The boundary between cytoarchitectonic areas 4 and 6 is marked with a nonuniform interrupted line.

der-required greater current. Shoulder, elbow, forearm, and wrist movements were evoked at some sites with $10 \mu \mathrm{A}$ or less. The lowest finger movement thresholds were $15 \mu \mathrm{A}$.

Hindlimb movements were evoked from both area 4 and area 6 sites caudal to and overlapping with the forelimb representation. Hindlimb movements included those of toc (flexion and extension of digit 1 [hallux], digits 1-5 together, or digits 2-5 together, abduction and adduction of digit 1), ankle (dorsiflexion, plantarflexion, internal and external rotation), knee(flexion, extension), and hip (flexion, extension, adduction, abduction, internal and external rotation). All of these movements were evoked at one or more sites with $\leq 20 \mu \mathrm{A}$ current except ankle dorsiflexion. Toe, ankle, and hip movements were evoked at some area 6 sites with under $10 \mu \mathrm{A}$. The lowest threshold movements, 1 toe extension and 1 ankle plantarflexion, were evoked with $4 \mu \mathrm{A}$. However, these lowest threshold movements were evoked from the most caudal part of the map and may therefore have been in the hindlimb representation of the primary motor cortex. There was no obvious boundary between the hindlimb representation of the SMA and that of the primary motor cortex either on the basis of thresholds (see above) or movement characteristics. Although the caudal limit of "noncontiguous" hindlimb movements (about $2 \mathrm{~mm}$ caudal to the area 4/area 6 boundary in both animals) might have been a candidate criterion for a primary motor cortex/SMA boundary, "noncontiguous" hindlimb sites were too sparse to delineate a clear boundary.

The tail representation extended $7 \mathrm{~mm}$ into area 4 from the caudal edge of area 6 . Tail movement sites, concentrated in the dorsal bank of the cingulatc sulcus in 1 hcmisphere (Fig. 4), extend well onto the medial surface of the hemisphere (Fig. 6) and onto the hemispheric convexity (Fig. 5) in the other maps elaborated. In all 3 cases, the tail representation was intermixed with that of the hindlimb. The evoked tail movements were typically limited to one point along the axis of the tail. Most movements transposed the distal tail towards the monkey's contralateral side, although ipsilateral, forward, and hindward tail movements were also evoked. Tail movements were sometimes seen in conjunction with either movements of the hips and legs or movements of the back. Tail movement thresholds were generally low, often below $10 \mu \mathrm{A}$. The lowest threshold tail movement required $5 \mu \mathrm{A}$.

Movements of the back were observed, not only in conjunction with tail movements, but also alone and in conjunction with neck and face, shoulder, and hip movements. Neck or back movements occurring simultaneously with other movements were evoked only with movements of adjacent body parts (e.g., 


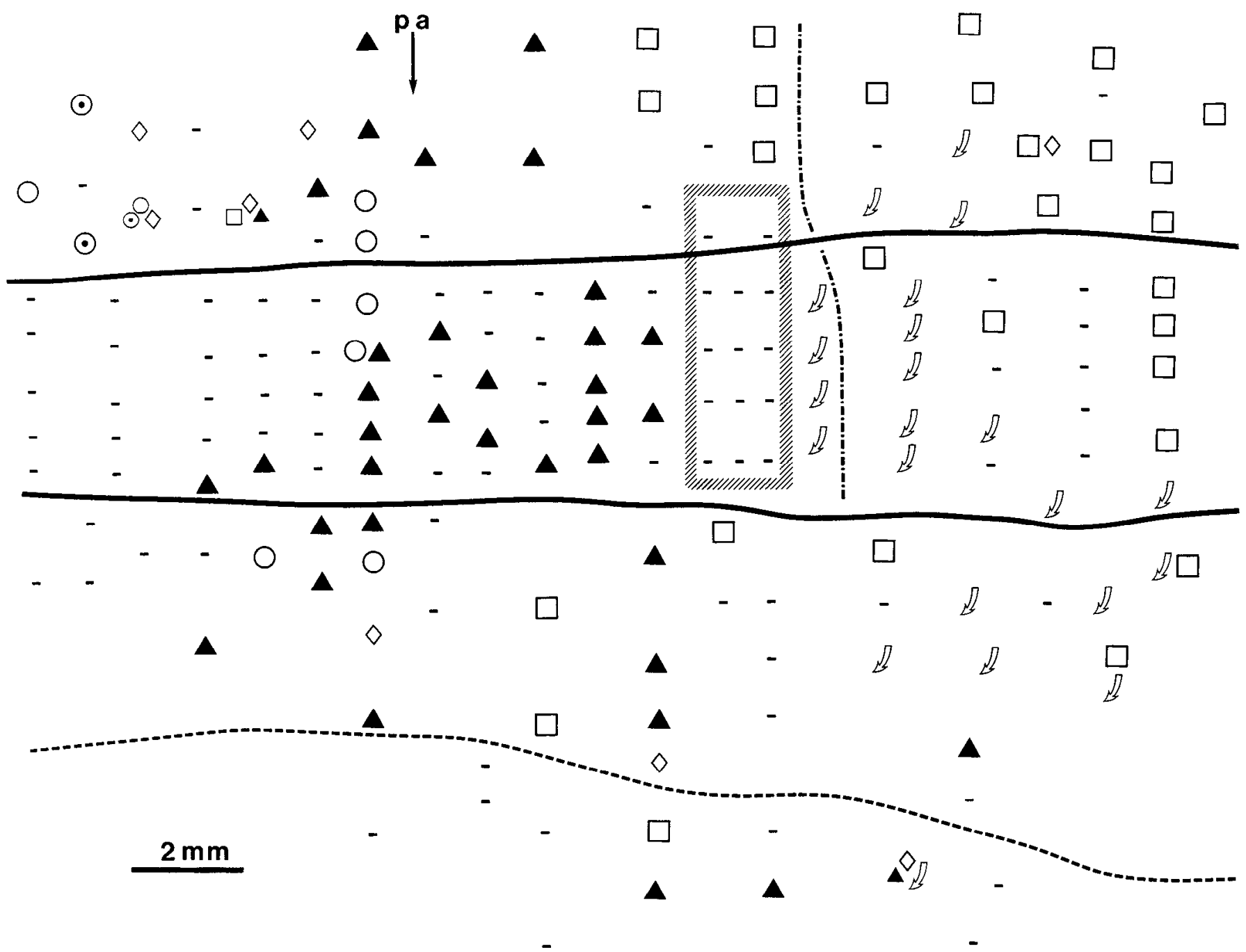

Figure 5. SMA somatotopy of the right hemisphere of the second rhesus monkey. Symbols are the same as in Figure 4. An area of gliosis of the medial wall and adjacent convexity of the hemisphere is circumscribed by the hatched box.

neck and upper back with shoulders, lower back with hips). Rotational movements of the back or neck were not observed, but it should be reiterated that the head was mechanically restrained. Typical movements included either ipsi- or contralateral deviation of the body below the activated muscles of the back or neck. Occasional instances of evoked abdominal muscle contraction were also observed.

Ipsilateral (without contralateral) movements of the hip or shoulder were evoked from 5 sites in the left hemisphere of the second animal. Bilateral facial movements were evoked from 9 sites in the same hemisphere. Bilateral hip movements were observed with back and tail movements at 1 site in the first animal.

A map comparing proximal and distal movement sites is shown for the left cortex of the second monkey in Figure 7. While there is a concentration of distal hindlimb sites in the most caudal (right) part of the map, particularly in the dorsal bank of the cingulate sulcus, it is likely that these points are in the primary motor cortex. Table 2 shows the distribution of proximal and distal forelimb movement sites over the cortical regions explored: the convexity of the hemisphere, the medial surface of the cortex, and the dorsal and ventral banks of the cingulate sulcus. No clear proximal-to-distal organization was observed.

\section{Discussion}

\section{Somatotopy}

\section{Gross somatotopy}

The prescnt microstimulation study of the SMA supports the view, originally proposed by Woolsey et al. (1952), that the SMA of macaque monkeys is a somatotopically organized cortical field with a rostrocaudal sequence of orofacial, forelimb, and hindlimb representations. Two major features of the data led to this conclusion: (1) In each case examined, a forelimb representation was found essentially centered on the medial surface of the hemisphere; and (2) rostral (on the medial surface) or rostrolateral (on the hemispheric convexity), depending on the case, there was an at least partially nonoverlapping region from which orofacial movements, including eye movements, were evoked. We know of no precedent for interpreting such a medially situated orofacial representation as anything but part of the supplementary motor cortex. It is noteworthy that most of the orofacial points on the hemispheric convexity are within 1 

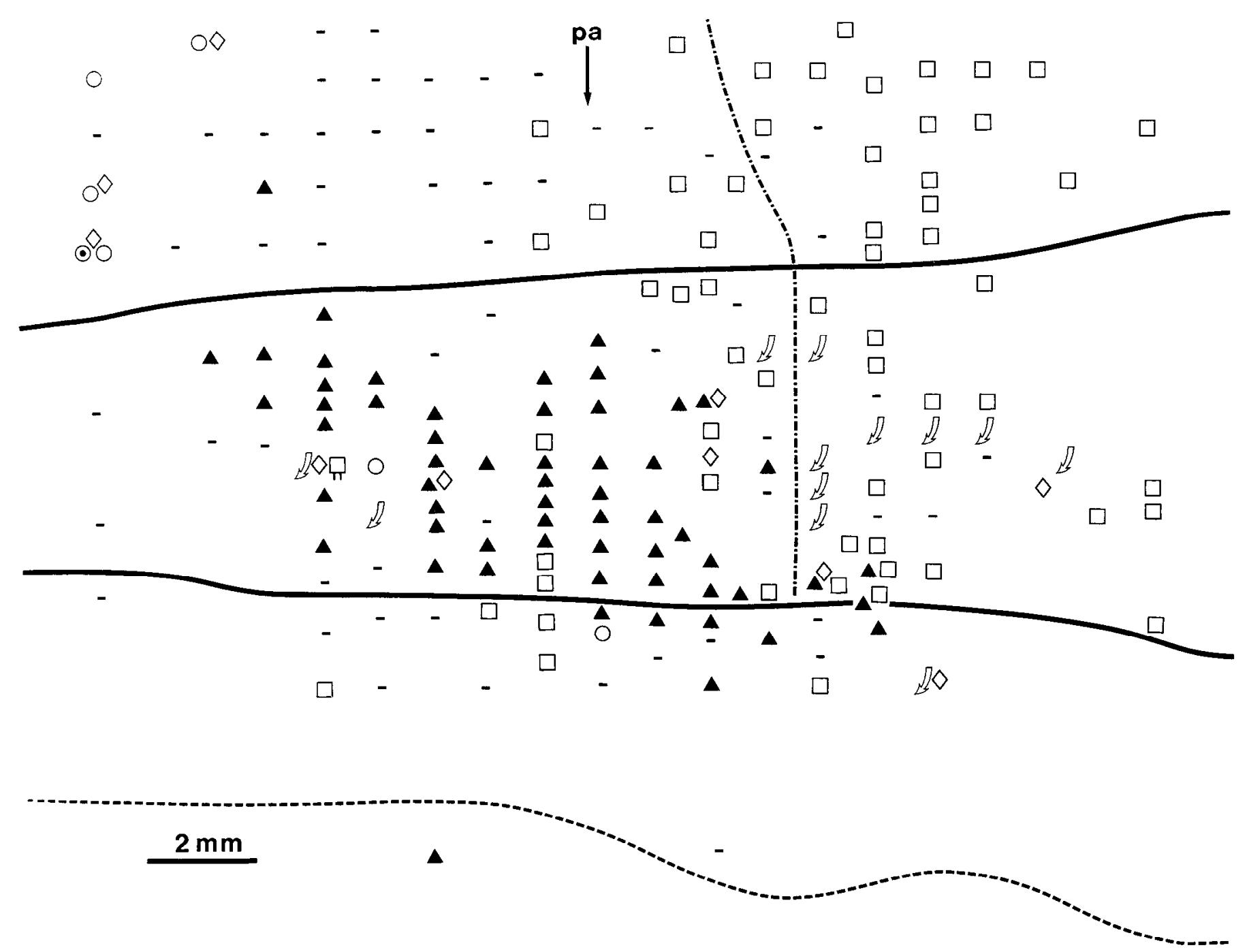

Figure 6. SMA somatotopy of the right and left hemispheres of the first rhesus monkey. Data points are primarily from the left hemisphere. Because of the trajectory of electrode penetration (see Materials and Methods), sites in the medial wall of the right hemisphere, and a few in the adjacent cingulate sulcus, were also explored; these data points are included in the map. Symbols are the same as in Figure 4.

cortical thickness of the medial surface and, as such, might justifiably be considered part of the medial wall in an alternative, equally valid, reconstruction method.

The present conclusion concerning SMA topography would, if accepted, bring the effects of microstimulation into line with conclusions based on anatomical (Jones and Powell, 1969; Muakkassa and Strick, 1979; Godschalk et al., 1984) and singleunit neurophysiological (Brinkman and Porter, 1979; Tanji and Kurata, 1982) experiments. Since the initiation of the present study, evidence for SMA somatotopy in another monkey species has become available. A microstimulation study of owl monkeys (Aotus trivirgatus) by Gould et al. (1986) demonstrated a rostrocaudal somatotopy in the SMA, one which included eye movements rostrally.

Although the findings in monkeys do not bear directly on the organization of SMA in humans, certain points seem pertinent. There has been a pattern of difficulty in demonstrating topography in the human SMA. Surface electrical stimulation studies were either equivocal (Woolsey et al., 1979) or negative (Penfield and Welch, 1951) in demonstrating somatotopy. There are, however, many problems with interpreting the results of those surface stimulation studies. In both studies, diseased tissue, usually a tumor, was generally in the vicinity of the stimulation sites. In the study by Woolsey et al. the difficulty in gaining access to the medial surface of the cortex with electrodes limited the number of SMA sites that could be stimulated. In the study of Penfield and Welch, stimulus parameters were not well controlled, leading to repetitive movements, complex synergies, and seizures. Perhaps for these reasons, the surface stimulation studies in humans offer little evidence of SMA somatotopy. Similarly negative results were obtained in an early examination of regional cerebral blood flow. Orgogozo and Larsen (1979) were unable to demonstrate a rostrodcaudal distinction among sites of increased blood flow during movements of the foot, hand, mouth, and eye. However, it has been argued that their blood flow measuring system did not have sufficient spatial resolution to identify different somatotopic areas of the SMA (Fox et al., 1985).

Against this negative evidence, results from stimulation in epileptic patients have been suggestive of an SMA somatotopy (Talairach and Bancaud, 1966; Talairach et al., 1967), but anatomical verification of stimulation sites was limited, the health 


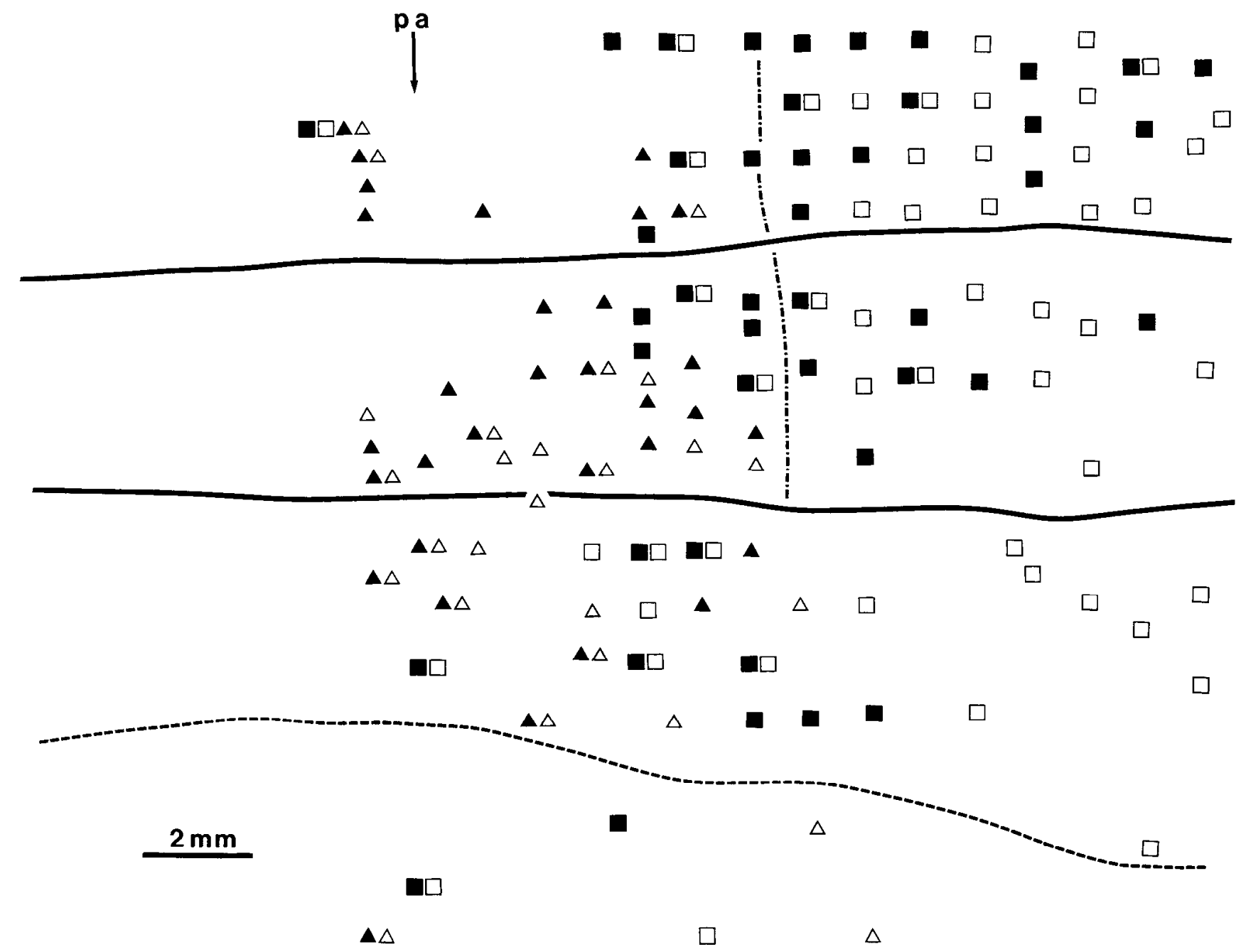

Figure 7. Distribution of proximal versus distal limb movement sites. Data are based on limb movements observed during stimulation in the left hemisphere of the second monkey, also illustrated in Figure 4. Symbols: open triangles, distal forelimb (fingers, wrist, forearm); filled triangles, proximal forelimb (elbow, shoulder); open squares, distal hindlimb (toes, ankle); filled squares, proximal hindlimb (knee, hip).

of the stimulated tissue was questionable, the movements evoked were often complex and difficult to interpret, and the degree of current spread to subcortical white matter could not be determined. More recently, however, Fox et al. (1985) reported that local cortical glucose metabolism, as measured with positron emission tomography, is greater rostrally in the SMA during practiced eye movements and greater caudally during practiced movements of the hand. Two interpretations of their findings seem possible: (1) the "eye movement region" is part of the SMA, or (2) that region lies in a separate cortical field. Ignoring, for the sake of discussion, species differences, the recent findings in monkeys argue for considering the eye movement zone to be within the SMA. Our results in Macaca mulatta and those of Schlag and Schlag-Rey (1985) in M. nemestrina have shown that the rostromedial eye movement zone is within area 6 . In addition, our results and those of Gould et al. (1986) in owl monkeys indicate a representational continuity between oculomotor sites and other orofacial movement sites. Thus, it is parsimonious to consider the "eye movement zone" of Fox et al. to be part of the SMA. In this view, then, the findings of Fox et al. offer the strongest support available for somatotopy in the human SMA. If this interpretation is correct, then the existence of SMA somatotopy in humans, Old World monkeys, and New
World monkeys (Welker et al., 1957; Gould et al., 1986) suggests that this trait is broadly, perhaps uniformly, represented in primates.

\section{Fine somatotopy}

Woolsey et al. (1952) reported that distal movement sites are primarily located on the dorsal convexity and the adjacent medial surface of the hemisphere, while proximal movements are represented in the dorsal bank of the cingulate sulcus and the adjacent medial surface of the hemisphere. These authors interpreted their results as indicative of an orderly proximal-todistal organization. Macpherson et al. (1982a), in contrast, reported that distal movement sites are located generally deep on the medial surface of the hemisphere but without an orderly progression. The present study offers strong support for neither the proximal-to-distal organization described by Woolsey et al. nor that reported by Macpherson et al.

\section{Methodological considerations}

\section{Chronic stimulation/recording procedure}

The present study involved chronic stimulation and recording methods over several months with transdural electrode penetrations. Clearly, this approach raises issues concerning the ac- 
curacy of stimulation site localization and the health of the brain over the course of the study. Since the primary conclusion of gross somatotopic organization in the SMA rests on the rostrocaudal distribution of movement sites, errors along this axis are of greatest concern. Marking pins (see Materials and Methods) were the primary basis for localization. They were locatcd within $1 \mathrm{~mm}$ of their predicted locations, $8 \mathrm{~mm}$ apart from each other. To some degree the accuracy of our reconstructions was confirmed by our ability to repeat penetrations at intervals of several weeks and obtain very similar data in 10 of 12 relevant tests (see Materials and Methods). As for potential brain damage, it appears that such damage was an important factor in our failure to evoke hindlimb movements from the medial surface of 1 hemisphere (Fig. 5). An area of gliosis was found to correspond closely to a region from which we were unable to evoke any movements, despite repeated efforts to do so. However, this small region aside, we do not believe that electrode-induced tissue damage affected our conclusions to any significant extent. There was, for example, no evidence that thresholds increased consistently across stimulation sessions in any part of the SMA map.

\section{Comparison with previous studies}

In addition to the study of Woolsey et al., SMA movements have been evoked with surface stimulation in macaques by Penfield and Welch (1951) and Hughes and Mazurowski (1962). Penfield and Welch did not observe a clear somatotopy; however, in their experiments the ventral bank of the cingulate sulcus as well as parts of the contralateral hemisphere were ablated, possibly compromising the surrounding tissue. Hughes and Mazurowski described a motor map on the median surface of the hemisphere of rhesus monkeys. Their large somatotopic map does not agree with that obtained by Woolsey et al., and presumably most of their effects were due to current spread.

Microstimulation has been tested in the SMA in an attempt to obviate the problem of current spread. However, microstimulation was either unsuccessful (Smith, 1979; Palmer et al., 1981; Wise and Tanji, 1981) or yielded relatively few evoked movements (Macpherson et al., 1982a). Macpherson et al., despite a specific effort to do so, failed to evoke any movements of the orofacial musculature, and the absence of such movements appears to have been central to their conclusions concerning a lack of somatotopy in the SMA. The lack of clear somatotopy in their data may be attributed to their use of standard microstimulation technique and the relatively low number of movements they could evoke. In one of their animals, Macpherson et al. may not have explored sufficiently far rostrally to evoke orofacial movements. In later work from the same laboratory, the limitations of "standard" microstimulation was circumvented to some degree by averaging electromyographic recordings during repeated presentations of single microstimuli to medial area 6 of the cortex (Wiesendanger, 1986). By plotting the frequency distribution of sites evoking forelimb EMG activity and sites evoking hindlimb activity along the rostrocaudal axis (Fig. 9 of Wiesendanger, 1986), it was shown that forelimb muscle representation, on the average, is rostral to hindlimb representation within area 6 .

\section{SMA excitability differences among primate species}

There are apparently species differences affecting motor cortical excitability. Standard microstimulation appears to be effective only in very localized regions of the SMA in macaques $[M$. fascicularis (Smith, 1979; Wise and Tanji, 1981; Macpherson et al., 1982a), M. nemestrina (Schlag and Schlag-Rey, 1985), and $M$. mulatta (Palmer et al., 1981; present study)], whereas movements are readily and reliably elicited from the SMA of owl monkeys with standard microstimulation (Gould et al., 1986).

\section{Modified microstimulation}

The 3 main differences between standard and modified stimulation technique are tip dimensions, train length, and application of ketamine. These are discussed below.

Tip dimensions and current spread. The effect of electrode tip size and current intensity on the activation of neural elements in the CNS has been studied both theoretically and experimentally. Since at large distances from the electrode (distances $>3$ times the exposed tip length, about $75 \mu \mathrm{m}$ in the present case), the effects of tip dimensions are negligible (Bagshaw and Evans, 1976; Ranck, 1979), current spread estimates made with standard microelectrodes can be used for large-tipped microelectrodes. Using Ranck's (1979) analysis based upon empirical estimates of current spread, our maximum current $(65 \mu \mathrm{A})$ could have activated the largest fibers up to $800 \mu \mathrm{m}$ from the electrode tip and small axons and cell bodies up to $500 \mu \mathrm{m}$ from the tip. These estimates are consistent with our observation that sites separated by $0.5 \mathrm{~mm}$ rarely evoked the same movement. However, there is an important difference between small- and largetipped electrodes. Based upon certain assumptions about electrode tip geometry, a neuron in the immediate vicinity of the electrode tip has a 10-fold lower threshold given a 10-fold smaller electrode tip (Ranck, 1979). This relation is due to the higher current density at the electrode tip of a smaller electrode for a given current. However, whereas small electrode tips preferentially activate the closest (and largest) neural elements at low current intensities, the same neural elements can be inhibited when the intensity of stimulation is increased (Ranck, 1975). Thus, for higher currents (presumably above 10 or $20 \mu \mathrm{A}$ ), standard microelectrodes and our modified microelectrodes spread current approximately equally, but microelectrodes with larger exposed tips may induce less inhibition of nearby neural elements.

Pulse train length and recruited pathways. Above about 30 msec, pulse train length has little effect on thresholds for evoking EMG activity from the primary motor cortex of cats (Asanuma et al., 1976) or monkeys (Kwan et al., 1978; A. R. Mitz and D. R. Humphrey, unpublished observations). In contrast, the longer pulse trains used in the present study enhanced the ability to evoke movements. The interpretation of these findings is uncertain, but it is tempting to speculate that longer pulse trains recruit pathways additional to those recruited by shorter pulse trains. Little is known about the excitability of either the corticospinal pathway or other pathways from the SMA to the motor apparatus. The increased effectiveness of stimulation with longer pulse trains might reflect the recruitment of efferent projections from the forelimb region of the SMA to the primary motor cortex. In support of this argument it has been reported that forelimb movements evoked with surface electrical stimulation from the SMA are abolished after primary motor cortex lesions in anesthetized monkeys (Wiesendanger et al., 1973). Since the corticocortical connections with the primary motor cortex appear to be somatotopic (see introduction), our observations are entirely consistent with the idea that this pathway mediates the motor effects observed in the present study. Al- 
ternatively, longer pulse trains might be necessary to activate the corticospinal projection originating from the SMA effectively (Murray and Coulter, 1981; Macpherson et al., 1982a). The terminal distribution of the SMA corticospinal system remains unknown, but if its input to $\alpha$-motoneurons is less direct or less efficacious than the corticospinal projection from the primary motor cortex, then longer pulse trains may be required to activate muscles from the SMA. Preliminary evidence from stimulus-triggered averaging experiments suggests that fewer direct, presumably corticomotoneuronal connections emanate from the SMA than from the primary motor cortex (Wiesendanger et al., 1985), but further work in this area is needed.

Use of ketamine. During the stimulation sessions, application of ketamine reduced the number of "spontaneous" movements by the animal, increasing the number of evoked movements that could be observed during SMA stimulation. The exact mechanism of the ketamine effect is not known, but it seems likely that the paucity of spontaneous movements or the inability to suppress evoked movements by coactivation of limb muscles greatly facilitated the observations.

\section{Cytoarchitectonics}

The cell measurement data presented in this study indicate that the boundary between area 4 and area 6 , as observed qualitatively, corresponds to the rostrocaudal level at which the largest pyramidal cells appear in substantial densities. If accepted as the area 6/area 4 boundary (see Figs. 4-6), and if the SMA is taken to lie entirely within area 6, then the SMA would appear to have a rather small hindlimb representation. However, the rostrocaudal transition from low to high giant cell densities is a gradual one, not lending itself to the identification of a clear breakpoint. It is entirely possible that the area $6 /$ area 4 boundary we drew based on our criteria, especially as depicted in Figure 4 , is rostral to the physiological SMA/primary motor cortex boundary. The cell measurements presented in Figure 2 indicate that an architectonic boundary $9 \mathrm{~mm}$ caudal to the posterior limit of the arcuate sulcus would be equally plausible to the one we drew, $7 \mathrm{~mm}$ caudal to that landmark. If this were the case, the SMA hindlimb representaton would appear to be roughly comparable to the orofacial representation in size. Despite this uncertainty, the location of the area 6/area 4 boundary with respect to the tail representation (of primary motor cortex, SMA, or both) agrees well with that described by Tanji and Kurata (1982) and Wise and Tanji (1981), especially for the cases presented in Figures 5 and 6.

\section{Theoretical considerations}

Taken together, the anatomical and physiological data from a broad variety of primate species lend little or no support to the hypothesis that the SMA functions as a nontopographically organized supramotor center (Eccles, 1982; Eccles and Robinson, 1984). Instead, whatever the rolc of the SMA in the cerebral control of behavior, it exerts that influence as a somatotopically organized system.

\section{References}

Asanuma, H., and A. P. Arnold (1975) Noxious effects of excessive currents used for intracortical microstimulation. Brain Res. 96: 103107.

Asanuma, H., and J. E. Ward (1971) Patterns of contraction of distal forelimb muscles produced by intracortical stimulation in cats. Brain Res. 27: 97-109.
Asanuma, H., A. Arnold, and P. Zarzecki (1976) Further study on the excitation of pyramidal tract cells by intracortical microstimulation. Exp. Brain Res. 26: 443-461.

Asanuma, H., R. S. Babb, A. Mori, and R. S. Waters (1981) Inputoutput relationships in cat's motor cortex after pyramidal section. J. Neurophysiol. 46: 694-703.

Bagshaw, E. V., and M. H. Evans (1976) Measurement of current spread from microelectrodes when stimulating within the nervous system. Exp. Brain Res. 25: 391-400.

Bonin, G. von, and P. Bailey (1947) The Neocortex of Macaca mulatta, University of Illinois Press, Urbana, IL.

Brinkman, C., and R. Porter (1979) Supplementary motor area in the monkey: Activity of neurons during performance of a learned motor task. J. Neurophysiol. 24: 681-709.

Brodmann, K. (1905) Beiträge zur histologischen Lokalisation der Grosshirnrinde. Dritte Mitteilung: Die Rindenfelder der Niederen Affen. J. Psychol. Neurol. (Leipzig) 4: 177-226.

Brodmann, K. (1909) Vergleichende Lokalisationslehre der Grosshirnrinde in ihren Prinzipien Dargestellt auf Grund des Zellenbaues, J. A. Bargh, Lepzig.

Fccles, J. C. (1982) The initiation of voluntary movements by the supplementary motor area. Arch. Psychiatr. Nervenkr. 231: 423-441.

Eccles, J. C., and D. N. Robinson (1984) The Wonder of Being $\mathrm{Hu}$ man. Our Brain and Our Mind, Free Press, Macmillan, New York.

Fox, P. T., J. M. Fox, M. E. Raichle, and R. M. Burde (1985) The role of cerebral cortex in the generation of voluntary saccades: A positron emission tomographic study. J. Neurophysiol. 2: 348-369.

Fritsch, G., and E. Hitzig (1870) Uber die elektrische erregbarkeit des grosshirns. Arch. Anat. Physiol. Wissenschaftl. Med. Leipzig, 300332. (Iranslation in Some Papers on the Cerebral Cortex, $\mathrm{G}$. von Bonin, ed., pp. 73-96, Charles C Thomas, Springfield, IL.)

Godschalk, M., R. N. Lemon, H. G. J. M. Kuypers, and H. K. Ronday (1984) Cortical afferents and efferents of monkey postarcuate area: An anatomical and electrophysiological study. Exp. Brain Res. 56: $410-424$.

Gottlieb, G. L., and G. C. Agarwal (1970) Filtering of electromyographic signals. Am. J. Phys. Med. 49: 142-146.

Gould, H. J., C. G. Cusick, T. P. Pons, and J. H. Kaas (1986) The relationship of corpus callosum connections to electrical stimulation maps of motor, supplementary motor, and the frontal eye fields in owl monkeys. J. Comp. Neurol. 247: 297-325.

Hughes, J. R., and J. A. Mazurowski (1962) Studies on the supracallosal mesial cortex of unanesthetized, conscious mammals. II. Monkey. A. Movements elicited by electrical stimulation. Electroencephalogr. Clin. Neurophysiol. 14: 477-485.

Jones, E. G., and T. P. S. Powell (1969) Connections of the somatic sensory cortex of the rhesus monkey. I. Ipsilateral cortical connections. Brain 29: 504-531.

Künzle, H. (1978) Cortico-cortical efferents of primary motor and somatosensory regions of the cerebral cortex in Macaca fascicularis. Neuroscience 3: 25-39.

Kwan, H. C., W. A. MacKay, J. T. Murphy, and Y. C. Wong (1978) Spatial organization of precentral cortex in awake primates. II. Motor outputs. J. Neurophysiol. 41: 1120-1131.

Leyton, A. S. F., and C. S. Sherrington (1917) Observations on the excitable cortex of the chimpanzee, orang-utan and gorilla. Q. J. Exp. Physiol. 11: 135-222.

Lilly, J. C., G. M. Austin, and W. W. Chambers (1952) Threshold movements produced by excitation of cerebral cortex and efferent fibers with some parametric regions of rectangular current pulses (cats and monkeys). J. Neurophysiol. 15: 319-341.

Macpherson, J. M., C. Marangoz, T. S. Miles, and M. Wiesendanger (1982a) Microstimulation of the supplementary motor area (SMA) in the awake monkey. Exp. Brain Res. 45: 410-416.

Macpherson, J. M., M. Wiesendanger, C. Marangoz, and T. S. Miles (1982b) Corticospinal neurones of the supplementary motor area of monkeys. A single unit study. Exp. Brain Res. 48: 81-88.

Mitz, A. R. (1984) A sequential pulse generator for producing true biphasic stimuli. Electroencephalogr. Clin. Neurophysiol. 57: 587590.

Muakkassa, K. F., and P. L. Strick (1979) Frontal lobe inputs to primate motor cortex: Evidence for four somatotopically organized "premotor" areas. Brain Res. 177: 176-182.

Murray, E. A., and J. D. Coulter (1981) Organization of corticospinal neurons in the monkey. J. Comp. Neurol. 195: 339-365. 
Orgogozo, J. M., and B. Larsen (1979) Activation of the supplementary motor area during voluntary movement in man suggests it works as a supramotor area. Science 206: 847-850.

Palmer, C., E. M. Schmidt, and J. S. McIntosh (1981) Corticospinal and corticorubral projections from the supplementary motor area in the monkey. Brain Res. 209: 305-314.

Pandya, D. P., and L. A. Vignolo (1971) Intra- and interhemispheric projections of the precentral, premotor and arcuate areas in the rhesus monkey. Brain Res. 26: 217-233.

Penfield, W. G., and E. Boldrey (1937) Somatic motor and sensory representation in the cerebral cortex of man as studied by electrical stimulation. Brain 60: 389-443.

Penfield, W., and K. Welch (1951) The supplementary motor area of the cerebral cortex. A clinical and experimental study. Arch. Neurol. Psychiatr. 66: 289-317.

Ranck, J. B. (1975) Which elements are excited in electrical stimulation of mammalian central nervous system: A review. Brain Res. 98: 417-440.

Ranck, J. B. (1979) Extracellular stimulation. In Electrophysiological Technique, D. R. Humphrey, ed., pp. 1-66, Society for Neuroscience, Bethesda, MD.

Schlag, J., and M. Schlag-Rey (1985) Unit activity related to spontaneous saccades in frontal dorsomedial cortex of monkey. Exp. Brain Res. 58: 208-211.

Smith, A. M. (1979) The activity of supplementary motor area neurons during a maintained precision grip. Brain Res. 172: 315-327.

Stoney, S. D., W. D. Thompson, and H. Asanuma (1968) Excitation of pyramidal tract cells by intracortical microstimulation: Effective extent of stimulating current. J. Neurophysiol. 31: 659-669.

Talairach, J., and J. Bancaud (1966) The supplementary motor area in man. (Anatomo-functional findings by stereo-electroencephalography in epilepsy). Int. I. Neurol. 5: 330-347.

Talairach, J., G. Szikia, P. Tournoux, A. Prossalentis, M. Bordas-Ferrer,
L. Covello, M. Jacob, and E. Mempel (1967) Atlas of Stereotactic Anatomy of the Telencephalon, p. 300, Masson and Cie, Paris.

Tanji, J., and K. Kurata (1982) Comparison of movement-related activity in two cortical motor areas of primates. J. Neurophysiol. 48 : 633-653.

Welker, W. I., R. M. Benjamin, R. C. Miles, and C. N. Woolsey (1957) Motor effects of stimulation of cerebral cortex of squirrel monkey (Saimiri sciureus). J. Neurophysiol. 20: 347-364.

Wiesendanger, M. (1986) Recent developments in studies of the supplementary motor area of primates. Rev. Physiol. Biochem. Pharmacol. 103: 1-59.

Wiesendanger, M., and R. Wiesendanger (1984) The supplementary motor area in the light of recent investigations. Exp. Brain Res. (Suppl. 9), pp. 382-392.

Wiesendanger, M., J. J. Seguin, and H. Künzle (1973) The supplementary motor area-A control system for posture? In Control of Posture and Locomotion, R. B. Stein, K. C. Pearson, R. S. Smith, and J. B. Redford, eds., pp. 331-346, Plenum, NY.

Wiesendanger, M., H. Hummelsheim, and J. M. Macpherson (1985) Microelectrophysiology of the supplementary motor area. Exp. Brain Res. 58: A1-17.

Wise, S. P., and J. Tanji (1981) Supplementary and precentral motor cortex: contrast in responsiveness to peripheral input to the hindlimb area of the unanesthetized monkey. J. Comp. Neurol. 195: 433-451.

Woolsey, C. N., P. H. Settlage, D. R. Meyer, W. Sencer, T. Pinto Hamuy, and A. M. Travis (1952) Patterns of localization in precentral and "supplementary" motor areas and their relation to the concept of a premotor area. Res. Publ. Assoc. Nerv. Ment. Dis. 30: 238-264.

Woolsey, C. N., T. C. Erickson, and W. E. Gilson (1979) Localization in somatic sensory and motor areas of human cerebral cortex as determined by direct recording of evoked potentials and electrical stimulation. J. Neurosurg. 51: 476-506. 